\title{
Adsorption-Desorption of Hexaconazole in Soils with Respect to Soil Properties, Temperature, and $\mathrm{pH}$
}

\author{
Zainol Maznah $^{1 *}$, Muhamad Halimah ${ }^{1}$, Ismail Bin Sahid ${ }^{2}$, Abu Seman Idris ${ }^{3}$ \\ ${ }^{1}$ Analytical and Quality Development Unit, Product Development and Advisory Services Division, Malaysian Palm Oil Board, No. 6, \\ Persiaran Institusi, Bandar Baru Bangi, 43000 Kajang, Selangor, Malaysia. \\ ${ }^{2}$ School of Environmental and Natural Resource Sciences, Faculty of Science and Technology, Universiti Kebangsaan Malaysia, 43600 \\ Bangi, Selangor, Malaysia \\ ${ }^{3}$ Ganoderma and Diseases Research for Oil Palm Unit, Biology Research Division, Malaysian Palm Oil Board (MPOB), No. 6, Persiaran \\ Institusi, Bandar Baru Bangi, 43000 Kajang, Selangor, Malaysia. \\ A R T I C L E I N F O \\ Article history: \\ Received 29 January 2016 \\ Accepted 30 May 2016 \\ Available online, ISSN: 2148-127X \\ Keywords: \\ Hexaconazole \\ Adsorption \\ Desorption \\ Freundlich \\ Kinetic \\ ${ }^{*}$ Corresponding Author: \\ E-mail: maznahz@mpob.gov.my \\ A B S T R A C T \\ The effect of temperature and $\mathrm{pH}$ on adsorption-desorption of fungicide hexaconazole \\ was studied in two Malaysian soil types; namely clay loam and sandy loam. The \\ adsorption-desorption experiment was conducted using the batch equilibration technique \\ and the residues of hexaconazole were analysed using the GC-ECD. The results showed \\ that the adsorption-desorption isotherms of hexaconazole can be described with \\ Freundlich equation. The Freundlich sorption coefficient $\left(\mathrm{K}_{\mathrm{d}}\right)$ values were positively \\ correlated to the clay and organic matter content in the soils. Hexaconazole attained the \\ equilibrium phase within $24 \mathrm{~h}$ in both soil types studied. The adsorption coefficient $(\mathrm{Kd})$ \\ values obtained for clay loam soil and sandy loam soil were $2.54 \mathrm{~mL} / \mathrm{g}$ and $2.27 \mathrm{~mL} / \mathrm{g}$, \\ respectively, indicating that hexaconazole was weakly sorbed onto the soils due to the \\ low organic content of the soils. Regarding thermodynamic parameters, the Gibb's free \\ energy change $(\Delta G)$ analysis showed that hexaconazole adsorption onto soil was \\ spontaneous and exothermic, plus it exhibited positive hysteresis. A strong correlation \\ was observed between the adsorption of hexaconazole and $\mathrm{pH}$ of the soil solution. \\ However, temperature was found to have no effect on the adsorption of hexaconazole \\ onto the soils; for the range tested.
}

\section{Introduction}

Adsorption and desorption are the main processes that affect the mobility, persistence, degradation, transport, and dissipation of pesticides and contaminants in the soil. Understanding the effects of these processes is important in order to obtain early information for predicting the environmental behaviour of pesticides and contaminants. Adsorption is a process in which the pesticide forms chemical bonds with colloidal materials such as soil organic matter and clay particles (Wauchope et al. 2002). Pesticide soil/solution distribution coefficients $\left(\mathrm{K}_{d}\right.$ values), commonly referred to as pesticide soil sorption values, are used to predict soil mobility of the compounds (Weber et al. 2004).

Investigations on adsorption-desorption phenomena of pesticides in soil have been reported for various soil types (Liu et al. 2010, Singh and Singh 2015, Rani and Sud 2015). It has been shown that adsorption and desorption of pesticides in soils depend on soil properties such as $\mathrm{pH}$, organic matter/clay content, chemical properties of the pesticide, and the environment (Ismail and Maznah 2006, Rani and Sud 2015). Aside from organic matter and clay content, the adsorption process is influenced by the size, shape, configuration, molecular structure, chemical functions, solubility, polarity, environmental temperature, and acid-base nature of the pesticide molecule itself (Arias-Estevez et al. 2006, Wauchope et al. 2002). The effect of $\mathrm{pH}$ on the adsorption of pesticides depends on the soil composition and the characteristics of the compound (Kah and Brown 2006). The $\mathrm{pH}$ related dependence of sorption is partly derived from the different proportions of ionic and neutral forms of the pesticide present at each $\mathrm{pH}$, i.e. by the $\mathrm{pKa}$ value (Gondar et al. 2013).Other than that, temperature also has a significant influence on sorption equilibrium and sorption kinetic processes. For most compounds, equilibrium sorption decreases with increasing temperature (Ten Hulscher and Cornelissen 1996), however for some cases, there is no effect of temperature on sorption equilibrium were found. Fernandez-Bayo et al. (2007) reported that under greenhouse conditions, where the temperature is high, the amount of insecticide sorption would diminish and implying increased released into the environment. 
Hexaconazole [(RS)-2-(2,4-dichlorophenyl)-1-(1H1,2,4-triazol-1-yl)hexan-2-ol] (Figure 1) is a systemic, broad-spectrum fungicide that is mainly used for controlling fungi, particularly ascomycetes and basidiomycetes. In Malaysia, hexaconazole was previously found to be effective in controlling white root disease in immature rubber and chrysanthemum, powdery mildew on roses (Lam and Chiu 1993, Lam and Lee 1993), and yellow sigatoka disease on banana (Chia 1997). Previously, Idris et al. (2004) have shown that hexaconazole is able to prolong the life of oil palm trees infected with Ganoderma. Recently, Maznah et al. (2015) have reported that half-life of hexaconazole in an oil palm plantation was found to be in the range 69.3 - 86.6 days.

Several studies have been carried out on the adsorption-desorption behaviour of hexaconazole in soils. Sharma et al. (2013) have reported the adsorption and leaching behaviour of hexaconazole in four different types of soils (alluvial, red, laterite, and black) from India. Singh (2002) also studied the adsorption-desorption of hexaconazole in five Indian types of soils. Other researchers also showed interest in the adsorption of hexaconazole on Korean and Chinese soils (Kyung et al. 2004, Han et al. 2012). Although many studies have been carried out on the adsorption of hexaconazole, they are limited to selected soils in specific countries. Therefore, in this study, two types of Malaysian soil with different properties are used to evaluate the effect of $\mathrm{pH}$ and temperature on the adsorption-desorption of hexaconazole. Furthermore, there is no published data available relating to the effect of temperature and $\mathrm{pH}$ on the adsorption-desorption of hexaconazole in the soils.

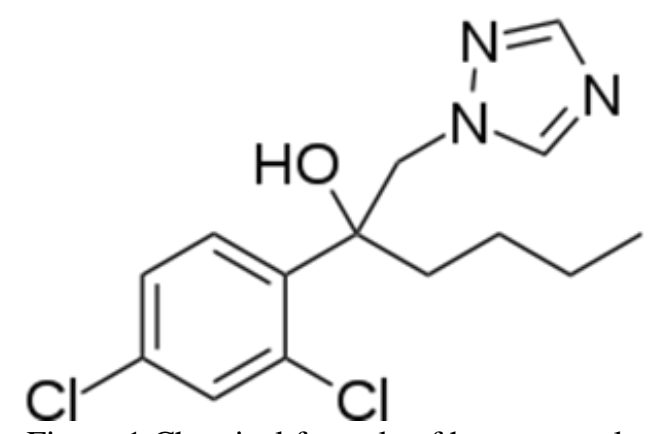

Figure 1 Chemical formula of hexaconazole

\section{Materials and Methods}

Analytical standard hexaconazole (99.5\% purity) was supplied by Riedel-de Haen, Germany. The stock solution of hexaconazole $(100 \mu \mathrm{g} / \mathrm{mL})$ was prepared in acetone (Merck, LiChrosolv ${ }^{\circledR}$ ) and stored in dark at $-4^{\circ} \mathrm{C}$ prior to use. Two types of soils from different cultivated oil palm plantations were used in the study. The soils samples were taken from 0 to $20 \mathrm{~cm}$ depth and all debris, stones, and roots were removed before the samples were air-dried and sieved through a $2 \mathrm{~mm}$ sieve. The physicochemical characteristics of the soil are tabulated in Table 1. All the parameters were determined using standard analytical procedures.

\section{GC-ECD Analysis}

Hexaconazole residues were quantified using a gas chromatograph (GC) equipped with an electron capture detector (ECD). The operating conditions adopted for the GC-ECD were similar to those published by Halimah et al. (2012).

\section{Adsorption Equilibrium Time}

The adsorption experiments were carried out in accordance with the standard batch equilibration method, using the batch equilibration technique (OECD, 2000). Two grams of the air-dried soils samples were placed in $50 \mathrm{~mL}$ centrifuge tubes and then $10 \mathrm{~mL}$ of $0.01 \mathrm{M} \mathrm{CaCl}_{2}$ solution of hexaconazole $(1.0 \mu \mathrm{g} / \mathrm{mL})$ were added. The mixture was then shaken in an orbital shaker at $150 \mathrm{rpm}$ with the temperature set at $30^{\circ} \mathrm{C}$. At different time intervals of $1,2,3,4,6,12,24$, and $48 \mathrm{~h}$, the mixture was taken out and centrifuged at $3000 \mathrm{rpm}$ for $20 \mathrm{~min}$ and the supernatant solution $(1.0 \mathrm{~mL})$ was filtered through a 0.45 $\mu \mathrm{m}$ filter before quantification. The tests were conducted in triplicate.

\section{Adsorption-Desorption Studies}

The adsorption isotherms were determined by using seven initial concentrations of hexaconazole ranging from 0.5 to $2.0 \mu \mathrm{g} / \mathrm{mL}$. The soil $(2.0 \mathrm{~g})$ and $10 \mathrm{~mL}$ of $0.01 \mathrm{M}$ $\mathrm{CaCl}_{2}$ solution were placed into $50 \mathrm{~mL}$ centrifuge tubes and shaken for $24 \mathrm{~h}$ in an orbital shaker. After equilibration had been reached, the soil slurry was centrifuged at $3000 \mathrm{rpm}$ for $20 \mathrm{~min}$. The supernatant layer was pipetted $(1.0 \mathrm{~mL})$ and sieved through a $0.45 \mu \mathrm{m}$ filter before it was analysed using the GC-ECD. The experiment was conducted in triplicate.

Desorption was studied using the same soils samples used for adsorption. After adsorption, the supernatant was decanted and was replaced with $10 \mathrm{~mL}$ fresh $0.01 \mathrm{M}$ $\mathrm{CaCl}_{2}$ solution. The mixture was again shaken on an orbital shaker for $24 \mathrm{~h}$ and centrifuged at $3000 \mathrm{rpm}$ for 20 min. The supernatant was filtered prior to quantification using the GC-ECD.

\section{Effect of Temperature}

The adsorption studies were carried out in triplicate at three levels of temperature $\left(25,30,35^{\circ} \mathrm{C}\right)$;representing the normal Malaysian weather conditions. The initial concentration used was $1.0 \mu \mathrm{g} / \mathrm{mL}$ and the experiment was carried out using the same procedure to that of the adsorption study.

\section{Effect of $p H$}

The effects of $\mathrm{pH}$ on the adsorption of hexaconazole were observed for three different levels of $\mathrm{pH}$; namely 3 , 7 , and 10 by adjusting the $0.01 \mathrm{M} \mathrm{CaCl}_{2}$ solution with concentrated hydrochloric acid $(\mathrm{HCl})$ and sodium hydroxide $(\mathrm{NaOH})$, respectively. All samples were prepared in triplicate for each respective $\mathrm{pH}$ value at an initial concentration of $1.0 \mu \mathrm{g} / \mathrm{mL}$. The experiment was carried out using the same procedure as that used in the adsorption study. 


\section{Statistical Analysis}

Soil sorption was characterized by the adsorption coefficient $\left(\mathrm{K}_{d}\right)$ using the following equation: $\mathrm{K}_{d}=\mathrm{C}_{\mathrm{s}} / \mathrm{C}_{\mathrm{e}}$, where, $\mathrm{C}_{\mathrm{s}}$ is the concentration of the analyte adsorbed into the soil $(\mathrm{mg} / \mathrm{kg})$ and $\mathrm{C}_{\mathrm{e}}$ is the equilibrium concentration of the solution $(\mathrm{mg} / \mathrm{L})$. The sorption isotherm parameters were calculated using the linear form of Freundlich equation as follows: $\ln \mathrm{C}_{\mathrm{s}}=\ln \mathrm{K}_{d}+1 / \mathrm{n} \ln \mathrm{C}_{\mathrm{e}}$, where $1 / \mathrm{n}$ and $\mathrm{K}_{d}$ are constants. The $\mathrm{K}_{d}$ and $1 / \mathrm{n}$ values were obtained by plotting the $\ln$ equilibrium concentration in the solution (x-axis) and the ln amount of hexaconazole sorbed into the soil (y-axis). The $n$ value represents the energy distribution of the adsorption site (Liu et al. 2010). The adsorption coefficient $\left(K_{d}\right)$ was also calculated as a function of organic carbon (OC) content and organic matter $(\mathrm{OM})$ of the soil in the following equation:

$$
\mathrm{K}_{\mathrm{OC}}=\mathrm{K}_{d} \times 10 / \% \mathrm{OC}
$$

Other parameters calculated for the adsorption process were Gibb's free energy change $(\Delta \mathrm{G}, \mathrm{cal} / \mathrm{mol})$ and Hysteresis coefficient $(H)$ (Lui et al. 2010, Sharma et al. 2013). The Gibb's free energy change $(\Delta G)$ was calculated for the adsorption-desorption isotherms according to the following equation: $\Delta \mathrm{G}=-\mathrm{RT} \ln \mathrm{K}_{\mathrm{OM}}$, where, $\mathrm{R}$ is the gas constant $(8.31 \mathrm{~J} / \mathrm{mol} \mathrm{K})$ and $\mathrm{T}$ is the temperature in Kelvin $(303 \mathrm{~K})$. The hysteresis coefficient $(H)$ was calculated for the adsorption-desorption isotherms using the following equation: $H=$ ( $n$ desorption) / ( $n$ adsorption), where, $n$ desorption and $n$ adsorption are the Freundlich constants obtained for the adsorption and desorption isotherms, respectively.

Table 1 Properties of soils studied

\begin{tabular}{l|cc}
\hline \multicolumn{1}{c}{ Parameters } & Clay loam soil & Sandy loam soil \\
\hline Site Texture class & NSCL & SSL \\
pH & 4.73 & 5.28 \\
Sand (\%) & 30.90 & 62.62 \\
Silt (\%) & 31.73 & 10.09 \\
Clay (\%) & 37.36 & 27.29 \\
Organic carbon (\%) & 1.12 & 0.86 \\
Organic matter (\%) & 3.91 & 3.00 \\
CEC (meq/100g) & 7.32 & 6.55 \\
\hline
\end{tabular}

NSCL: Negeri Sembilan Clay loam; SSL: Selangor Sandy loam

\section{Results and Discussion}

\section{Adsorption Equilibrium Time}

The adsorption equilibrium time for hexaconazole in the two types of soils studied is presented in Figure 2. The results showed that hexaconazole attained the equilibrium phase within $24 \mathrm{~h}$ for both types of soil studied. The adsorption kinetics exhibited two distinct phases; a very rapid adsorption in the initial phase (within $4 \mathrm{~h}$ ) and then followed by slow adsorption. This phenomenon is due to the fact that a large number of vacant surface sites are available for adsorption during the initial stage, and that the remaining vacant surface sites are difficult to be occupied due to the repulsive forces between the solute molecules on the solid and bulk phase (Liu et al. 2010). A similar trend has been reported for other compounds such as diuron (Liu et al. 2010), lindane, carbofuran, and methyl parathion (Rama Krishna and Philip 2008) in various soils.

\section{Adsorption-Desorption Studies}

The calculated Freundlich parameters, Gibb's free energy change $(\Delta \mathrm{G})$, and Hysteresis coefficient $(H)$ of hexaconazole adsorption-desorption in clay loam and sandy loam are given in Table 2. All adsorption data fitted very well with the Freundlich adsorption isotherm, as indicated by the high regression coefficients values $\left(r^{2}>\right.$ 0.98). The adsorption isotherms of hexaconazole resembled the C-type (clay loam) and S-type (sandy loam) of adsorption isotherms (Giles et al. 1960). When the Freundlich constant $n$ value for hexaconazole in the sandy loam was close to 1 , adsorption would be linearly proportional to the equilibrium solution concentration (Rama Krishna and Philip 2008). Singh (2002) suggested that hexaconazole which contains hydroxyl group shows S-type adsorption isotherm indicating that the nonlinearity of the adsorption isotherms is probably due to the interaction of hydroxyl group of hexaconazole and organic mineral fraction in the soil.

The $\mathrm{K}_{d}$ values obtained in this study for clay loam and sandy loam were 2.54 and 2.27 , respectively. The $\mathrm{K}_{d}$ value increased as the organic matter content increased and the highest adsorption of hexaconazole was observed on clay loam soil. The calculated data showed that clay soil adsorbed higher amount of hexaconazole per unit carbon; therefore, a higher $\mathrm{K}_{\mathrm{oc}}$ value was observed for the soil with high clay content. The $\mathrm{K}_{\mathrm{oc}}$ values calculated for clay loam and sandy loam were 44.25 and 27.27, respectively. Previous studies by Sharma et al. (2013) and Singh (2002) have shown that the adsorption of hexaconazole is correlated to soil organic matter content. Generally, adsorption of pesticides is positively correlated to organic matter, clay content, and CEC values of the soil (Liu et al. 2010, Ismail and Maznah 2006, Arias-Estevez et al. 2006).

The desorption parameters of hexaconazole in the two types of soil studied are presented in Table 2 . The $\mathrm{K}_{\text {des }}$ value obtained from the Freundlich equation for clay loam (1.64) was slightly lower than that of sandy loam $(2.48$ $\mathrm{mL} / \mathrm{g}$ ). From the study, the $\mathbf{K}_{\text {des }}$ of the sandy loam soil was higher than that of clay loam and this could be due to the lower content of organic matter and clay in the soil. The hysteresis $(H)$ value for clay loam was 0.53 and for sandy loam was 0.999. These findings indicate that hexaconazole exhibits positive hysteresis especially in clay loam soil. The results of this study are in accordance with those obtained by Sharma et al. (2013), in which it reported that hexaconazole had exhibited positive hysteresis varied from 0.03 to 0.15 .

\section{Effect of Temperature}

The effect of temperature on the adsorption of hexaconazole in the soils is shown in Figure 3. It can be seen that the adsorption of hexaconazole was not affected when the temperature was increased. This may be because the three selected temperature levels $\left(25,30,35^{\circ} \mathrm{C}\right)$ were 
Table 2 Freundlich parameters $\left(\mathrm{K}_{d}, 1 / \mathrm{n}, \mathrm{r}^{2}\right)$, Gibb's free energy change $(\Delta \mathrm{G})$ and Hysteresis coefficient $(H)$ for hexaconazole adsorption-desorption

\begin{tabular}{l|cc}
\hline Parameter & Clay loam soil & Sandy loam soil \\
\hline Linear equation & $\mathrm{y}=1.538 \mathrm{x}-0.931$ & $\mathrm{y}=0.923 \mathrm{x}-0.818$ \\
$\mathrm{~K}_{d}$ & 2.54 & 2.27 \\
$1 / \mathrm{n}$ & 1.538 & 0.923 \\
$\mathrm{r}^{2}$ & 0.989 & 0.992 \\
$\mathrm{~K}_{\mathrm{oc}}$ & 44.25 & 27.27 \\
Linear equation & $\mathrm{y}=0.814 \mathrm{x}+0.496$ & $\mathrm{y}=0.922 \mathrm{x}+0.907$ \\
$\mathrm{~K}_{\text {des }}$ & 1.64 & 2.48 \\
$1 / \mathrm{n}$ & 0.814 & 0.922 \\
$\mathrm{r}^{2}$ & 0.988 & 0.982 \\
$\Delta \mathrm{G}^{\mathrm{o}}(\mathrm{kJ} / \mathrm{mol})$ & -2.35 & -2.06 \\
$H$ & 0.530 & 0.999 \\
\hline
\end{tabular}

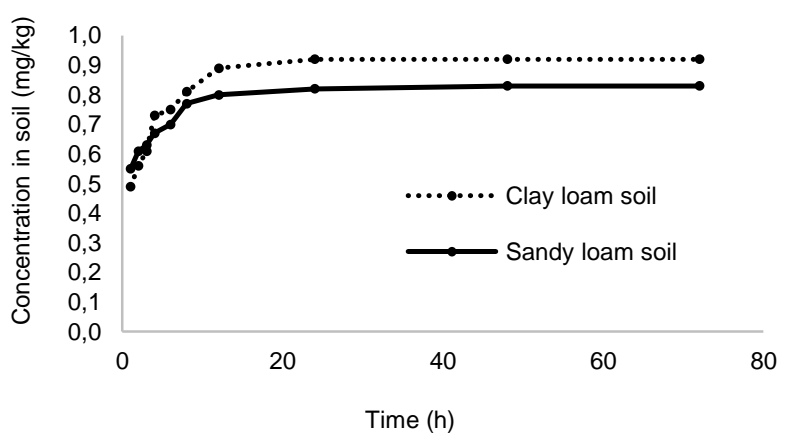

Figure 2 The adsorption equilibrium time of hexaconazole in soils

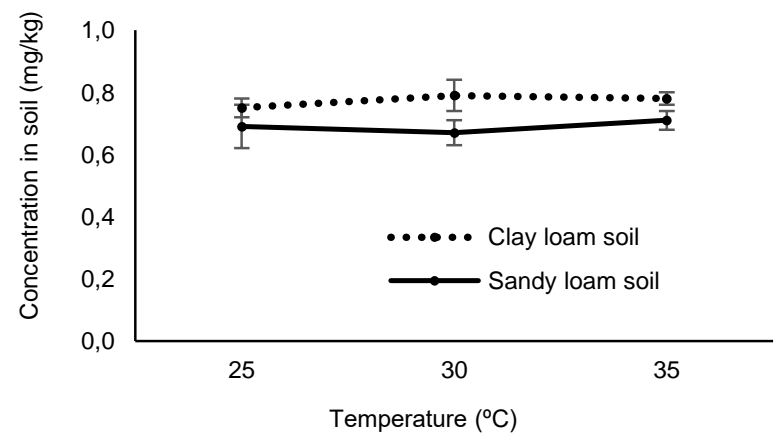

Figure 3 Effect of temperature on adsorption

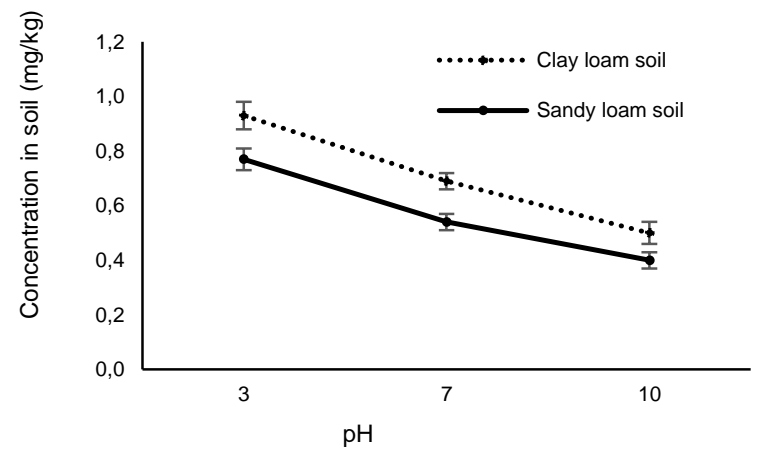

Figure 4 Effect of $\mathrm{pH}$ on adsorption within $10^{\circ} \mathrm{C}$. Therefore, the effect of temperature on the adsorption of hexaconazole was not clear. Regarding the thermodynamic parameters, the Gibb's free energy change $(\Delta \mathrm{G})$ provides additional information regarding the energy changes involved during the temperaturedependent sorption process (Broznic and Milin 2012). In this study, the $\Delta \mathrm{G}$ values obtained for clay loam and sandy loam were -2.35 and -2.06 , respectively. The small negative values of $\Delta \mathrm{G}^{\circ}$ indicate the exothermic nature of the reaction (Rama Krishna and Philip 2008).

\section{Effect of $p H$}

The influence of $\mathrm{pH}$ on adsorption of pesticides in soils has been reported in previous studies (Rama Krishna and Philip 2008, Liu et al. 2010). As expected, the adsorption of hexaconazole was higher at $\mathrm{pH} 3$ compared to $\mathrm{pH} 7$ and 10 (Figure 4). The results are in agreement with those obtained by Arias et al. (2006) in which it was reported that by lowering the $\mathrm{pH}$ from 5.5 to 2.5 , the adsorption of penconazole onto vineyard soils substantially increased. At a lower $\mathrm{pH}$, a significant proportion of fungicide is positively charged, therefore it is attracted to the negative charge of the soil colloids (Arias et al. 2006).

In conclusion, the adsorption-desorption studies of hexaconazole indicate that hexaconazole is weakly sorbed in Malaysian soils with low organic matter and clay content. The adsorption isotherms fitted very well with the Freundlich equation $\left(r^{2}>0.98\right)$. The Freundlich sorption coefficient $\left(\mathrm{K}_{d}\right)$ values were positively correlated tothe clay and organic matter content in the soils. Adsorption of hexaconazole was much higher at lower $\mathrm{pH}$ (3) compared to higher $\mathrm{pH}$ (7 and 10). There was no significant correlation observed regarding the adsorption of hexaconazole and the increase in temperature. The findings of the present study can be used to make predictions on the leaching capability of hexaconazole in Malaysian soils, in order to minimize contamination of groundwater resources.

\section{Acknowledgements}

The authors would like to express great appreciation to the Director General of MPOB for giving MPOBGSAS scholarship and approval to publish these findings. Thanks are due to all staff of Pesticide Laboratory MPOB and Makmal Rumah Tumbuhan, UKM for their support and technical assistance.

\section{References}

Arias M, Paradelo M, Loa Pez E, Simal-Gaa Ndara J. 2006. Influence of $\mathrm{pH}$ and soil copper on adsorption of metalaxyl and penconazole by the surface layer of vineyard soils. J. Agric Food Chem 54:8155-8162.

Arias-Estevez M, Lopez-Periago E, Martinez-Carballo E. 2006. Carbofuran sorption kinetics by corn crop soil. Bull Environ Contam Toxicol 77:276-273.

Broznic D, Milin C. 2012. Effects of temperature on sorptiondesorption processes of imidacloprid in soils of Croatian coastal regions. Journal of Environmental Science and Health B 47:779-794. 
Chia TH. 1997. Hexaconazole (Anvil 5SC) - A broad spectrum systemic fungicide for diseases control in some plantation crops. The Planter 73(852):129-135.

Fernández-Bayo JD, Nogales R, Romero E, 2007. Improved retention of imidacloprid (Confidor $\left.{ }^{\circledR}\right)$ in soils by adding vermicompost from spent grape marc. Science of the Total Environment, 378(1): 95-100.

Giles CH, MacEwan TH, Nakhwa SN, Smith D. 1960. Studies in adsorption. Part XI. A system of classification of solution adsorption isotherms, and its use in diagnosis of adsorption mechanisms and in measurement of specific surface areas of solids. Journal of the Chemical Society: 3973-3993.

Gondar D, López R, Antelo J, Fiol S, Arce F. 2013. Effect of organic matter and $\mathrm{pH}$ on the adsorption of metalaxyl and penconazole by soils. Journal of Hazardous Materials 260: 627633.

Halimah M, Maznah Z, Ismail S, Idris AS. 2012. Determination of hexaconazole in field samples of an oil palm plantation. Drug Test. Analysis 4 (Suppl. 1):112-117.

Han M, Song L, Wang W. 2012. Adsorption-desorption characteristics of hexaconazole in soils. Environmental Chemistry 3:017

Idris AS, Ismail S, Ariffin D, Ahmad H. 2004. Prolonging the productive life of Ganoderma infected palms with hexaconazole. MPOB Information Series. MPOB TT No. 214

Ismail BS, Maznah Z. 2006. Adsorption-desorption and mobility of fenvalerate in three tropical agricultural soils. AmericanEurasian Journal of Agriculture \& Environmental Science 1(2):160-168.

Kah M, Brown CD. 2006. Adsorption of ionisable pesticides in soils. In Reviews of Environmental Contamination and Toxicology. Springer New York.

Kyung KS, Lee BM, Ihm YB, Lee YD, Han SS, Choi JH, Kim JH, Ryu GH, Lee JK, 2004. Adsorption and leaching characteristics of fungicide hexaconazole. The Korean Journal of Pesticide Science 8:46-53

Lam CH, Chiu SB. 1993. Hexaconazole (Anvil 5SC), a costeffective fungicide for controlling white root disease in immature rubber. The Planter 69:465-474.
Lam CH, Lim TK. 1993. Efficacy of hexaconazole for the control of white rust on chrysanthemum and powdery mildew on roses. International Journal of Pest Management 39(2):156-160.

Liu Y, Xu Z, Wu XW, Gui W, Zhu G. 2010. Adsorption and desorption behavior of herbicide diuron on various Chinese cultivated soils. J Hazard Mater178:462-468

Maznah Z, Halimah M, Ismail BS, Idris AS. 2015. Dissipation of the fungicide hexaconazole in oil palm plantation. Environ Sci Pollut Res 22: 19648-19657.

OECD. 2000. Guidelines for testing of chemicals, Section 1 (106): Adsorption-Desorption using batch equilibrium method in soils. Environmental Health and Safety Division, Organisation for Economic Co-operation and Development (OECD), Environment Directorate, Paris, France.

Rama Krishna K, Philip L. 2008. Adsorption and desorption characteristics of lindane, carbofuron and methyl parathion on various Indian soils. J Hazard Mater 160:559-567.

Rani S, Sud D. 2015. Effect of temperature on adsorptiondesorption behaviour of triazophos in Indian soils. Plant, Soil Environ 61(1): 36-42.

Sharma K, Sharma RK, Joseph PE, Saha S, Walia S. 2013. Sorption and leaching behavior of hexaconazole as influenced by soil properties. Toxicological \& Environmental Chemistry 95:10901098

Singh N. 2002. Sorption behavior of triazole fungicides in indian soils and its correlation with soil properties. J Agric Food Chem 50:6434-6439

Singh N, Singh SB. 2015. Adsorption and leaching behaviour of bispyribac-sodium in soils. Bull Environ Contam Toxicol 94:125-128

Ten Hulscher TE, Cornelissen G. 1996. Effect of temperature on sorption equilibrium and sorption kinetics of organic micropollutants-a review. Chemosphere, 32(4): 609-626.

Wauchope RD, Yeh S, Linders JBHJ, Kloskowski R, Tanaka K, Rubin B, Katayama A, Kordel W, Gerstl Z, Lane M, Unsworth JB. 2002. Pesticide soil sorption parameters: theory, measurement, uses, limitations and reliability. Pest Manag Sci 58:419-445.

Weber JB, Wilkerson GG, Reinhardt CF. 2004. Calculating pesticides sorption coefficients $\left(\mathrm{K}_{d}\right)$ using selected soil properties. Chemosphere 55:157-166. 